\title{
Relevant Economic Factors Affecting Franchise Operations in the Services and Trade Sectors
}

\author{
HASANOV Anar ${ }^{1}$ \\ ${ }^{1}$ Nero, Istanbul, (TURKEY) \\ Email:anarik47@hotmail.com
}

\begin{abstract}
The paper analyzes the basic elements of the economic efficiencies of franchises in the field of trade and services in Serbia. Basic economic performance indicators of are analyzed, which include payback period, an accounting rate of return, net present value, profitability level and break-even analysis. External factors affecting the overall business, especially the choice of locations, were analyzed through the impact of the standard of living of the population. Calculations and analyzes were made on the basis of the balance sheet data of individual franchises and statistics on the trends of living standards for individual cities and regions in the Republic of Serbia.

Population and standard of living have proven to be a significant factor in business decision making. Business premises can be reasonably opened in areas with an average population of about $3.33 \%$ of the total population. In regions and cities with a lower percentage of population, it is justified to open franchises if they are situated in high-frequency locations such as highways and/or tourist destinations.

It is important to note that for management, in addition to all the indicators analyzed, it is very important to maintain standards that include recognizable appearance, standard quality offer, well-trained staff and everything else that the brand carries with it.
\end{abstract}

Keywords: franchise, basic elements of franchise agreements, economic indicators of business, living standard of the population, regression analysis

JEL: 010

UDK: 339.187.44

330.552:338.46

330.552:339.1

\section{Introduction}

The main objective of the paper is to show the importance and role of internal and external analyzes in evaluating franchises in Serbia. The first analysis deals with the calculation of basic economic indicators on the performance, profitability of companies and return on investment. The second analysis deals with an external factor, that is, how and in what way the living standards of the population affect the chances of opening new franchises in Serbia in the field of services and trade. The results show very clearly the conditionality and impact of living standards on performance and economic efficiency, especially the choice for the location of a potential franchise operation. The calculations were made based on the analysis of the databases formed in the first case by downloading the balance sheets of individual franchises. The second analysis was made based on statistics for individual cities and regions in the Republic of Serbia. 
The text provides an overview of the literature, in particular attitudes and opinions that indicate the importance of monitoring key business indicators, return on investment, and assessing broader economic indicators on the country's economy and developments in the standard of living of the population. The methodology for calculating economic performance indicators and the impact of living standards is universal and can be used in the example of any country, region or area.

\section{Franchise Operations and Intertwined Goals of International Corporations and Domestic Companies}

In the business operations of signing and starting a franchise permeate the intertwined goals of international corporations and domestic companies. [1] points out that the primary goal of international companies in signing a franchise agreement is a strategic way to reduce dependence on domestic demand and grow new, future revenue and profit centres around the world. Expanding the brand globally through franchising involves low risk, requires minimal investment, and offers huge potential to increase capacity. Unlike them, the domestic companies are looking for: (1) a reputable brand that means a product guarantee for the customer and allows him to feel at home anywhere in the world. This is why the franchise system takes care of who to entrust its franchise with, since one business unit operating poorly is enough to cause great damage; (2) a simple, attractive product or service that should focus on products that are not of short-life, that do not have large fluctuations in volume and revenue during the year of selling; and (3) a distinctive, elaborate business system from which a domestic company or entrepreneur gains the right to use a brand, product or service, as well as years of franchisee experience.

The interconnectedness of franchise operations for the donor and the recipient is a shared success that is measured by sales growth, good reputation, brand preservation, and in particular, long-term growth and development prospects. However, the common goal is often the result of long, complicated and strictly signed commitments. In this regard, it is very important as Stanton [2] states that "franchising is an attractive option for entrepreneurs because of "the turnkey" process, established brand and proven experience of the whole system." However, every entrepreneur or franchisee must be aware of the following five issues: (1) whether signed contracts, arrangements or franchising can be a profitable business; (2) whether key performance indicators - KPIs - are known and can be identified and learned, measuring the underlying processes and success factors while helping to understand the complete franchise business, that is, identify the underlying drivers of success; (3) whether industry status and market conditions have been identified and assessed; (4) whether business arrangements that are known and understood are selected and (5) whether effective and developed management functions are in place in major management areas such as marketing, HRM, ITC, real estate and day-to-day operations.

As can be seen, it is very important that each aspect, factor and business relationship of the two partners is realistically defined, that the global aspect and success of the brand are reduced and seen in the prism of the local economy, habits, business culture and in particular, the habits and behaviour of local consumers. Franchising World [3] highlights and defines good practice for improving the franchise business. Practical and effective approaches to business improvement are: (1) assessing trends and identifying areas for improvement are key to success and maximizing profitability. The first thing to do is identify the data that is needed to understand how to and where the business can be improved; (2) evaluate trends, benchmarks and comparisons with other franchisees; (3) measure and maximize performance, such as key performance indicators - KPIs and at the same time, to share data with employees to maximize their role, vision commitment and level of responsibility. Other actions could be answering the 
questions by monitoring employees' performance - how can the efficiency of the company in general and the efficiency of employees in particular be improved; identifying demand for products and services, and exploring the habits and preferences of the population.

In addition, it is very important to know the efficiency and return on investment data, the seasonal impact on sales, the movement of relevant prices of other products and overhead costs; and (4) accurately defining relevant and valid performance metrics across all franchise locations. Set a goal, measure the stated target, and analyze those results to get the expected results that each franchisee will pass.

Modern market business is permeated by radical and complex qualitative-quantitative changes that lead to completely new demands in all areas of life and work of individuals, businesses and national economies. Technical progress and technological advancement condition the continuous growth and development of existing areas of economy, as well as the emergence of new industries, which further leads to the "arrangement" of the new situation on the world, regional and local markets. The improvement of existing areas of business, as well as the development of new areas, implies the need for new levers and drivers, both in the sphere of financial activity and in the field of appropriate legal regulation and harmonization of these new relations. New business modalities and new ways of connecting among market participants are emerging, requiring new forms of financing to function smoothly. The trend of constant change, caused by a precarious market situation, creates new "stimuli" for development that directly stimulate growth and development of economy, whose positive effects lead to broader social well-being.

As a result of the search for the optimal solution for expanding the market and finding new opportunities, apart from mergers and acquisition, a new, atypical form of market financing franchising - has emerged. The meaning of franchising comes from the fact that the right to use the property is more valuable than the ownership of the property itself. The ownership of capital, as a social relationship that allows cash assets to be fertilized, is not the only most important item in a business, but the "ceding" of its use in the function of producing and increasing capital. Franchising is based on the business philosophy that "ownership is an exceptional luxury". Franchising is a form of business integration in which an explicit and successful business concept is transformed into another organization. Thus, available capabilities and resources are absorbed.

Franchising is a widespread concept of business cooperation that provides an incentive for developing entrepreneurial potential and the economy. It contributes to stimulating entrepreneurs with insufficient experience to start their own entrepreneurial venture and gain an enviable market position over time. The franchisor invests his initial capital, knowledge and experience, and the franchisee contributes through the additional investment of capital, business experience gained through doing business in various markets. Franchisees use a sophisticated business system; therefore, the business takes on the dimensions of a less risky business.

Due to the range of benefits it provides to both users and providers of the system, franchising is in the phase of worldwide expansion. Worldwide franchising is synonymous with McDonald's American fast food restaurants that provide identical services worldwide.

The actuality of this topic is certainly contributed by the fact that franchise systems influence the creation of a large number of business units in the short term, the creation of new jobs and the involvement of domestic capital, which is of particular importance in developing countries. 


\section{Franchisees and Adaptation Strategy to Local Circumstances and Needs}

World Franchising [3] defines franchises as "a system of commercialization of products and/or services and or technology, based on the close and continuous cooperation of the entity, legally and financially specific and independent, the franchisor and its franchisees, whereby the franchisor grants its franchisees the right and imposes an obligation to run the business in accordance with the franchisor concept. The ceded right authorizes and obliges the franchisee, in exchange for direct or indirect financial compensation, to use the mark and, or brand of the product and or services, know-how and other intellectual property rights, aided by the continued provision of commercial and, or technical assist with and during the duration of the written franchise agreement concluded between the parties to that end."

Unlike the previous franchise definition, [4] defines a franchise agreement as "an oral or written agreement for a fixed or indefinite period, by which one person assigns to another person the use of a company, service mark, or other feature, and within which there is a common interest in placement of goods or services in bulk, retail, lease or otherwise under that license." The emphasis is on a common interest in the marketing of goods or services and the joint growth and development.

From the above definitions, we conclude that the franchise is a model of contractual cooperation between legally independent entities whereby a "leader" company exercises its licensed right to sell its products and services to small or medium-sized enterprises, using both its brand and its enviable experience when performing the activity. Franchising is a proven way for small and medium-sized businesses to thrive in business using someone else's experience and knowledge in running a given business.

The three basic elements of each franchise agreement are:

- Reputable brand - it means the customer a guarantee of the product and allows him to feel at home anywhere in the world. This is precisely why the franchise system cares about who to entrust its franchise with, because one business unit that does poorly is is sufficient to do great damage;

- A simple, attractive product or service - should focus on non-short-lived products that do not have large fluctuations in volume and income during the year;

- Recognizable, developed business system - An entrepreneur acquiring a franchise acquires the right to use a brand, product or service, as well as years of experience of the franchisor.

- The franchise fees.

The emergence of any company that is willing to expand its network through franchisees should be seen as an opportunity for a large number of small and medium enterprises. From an entrepreneurial point of view, this means the possibility of opening one's own business with faster and easier entry into the supply market, reduced business risk and reasonable profit in business, as well as faster return on invested capital.

Franchise business is accompanied by reduced market and financial risk, since the already acquired reputation of the franchisor, with the developed marketing system facilitates their market penetration with a very small degree of own investment. Franchising is a package of rights including the brand, design, knowledge and ongoing support provided by the franchisor to the recipient with appropriate compensation and with the obligation not to violate the rights of either party. Entering entrepreneurship through a franchise is about starting your own business, which does not mean being left to yourself because franchising provides a complete tried and tested business system, brand, manuals, training, equipment and other support services. 
In addition to all the benefits, there is a need to mention the other side of the franchising business, which is the fact that the profit in the franchise is less than the profit that would be earned in the ownership. The future franchisor must deal with the inevitable problems of communication and work with franchisees. Initial investing can be expensive for a potential business entity, but in the long run it solves the problem of business expansion, as well as the lack of three basic factors for business: time, money and motivated staffing.

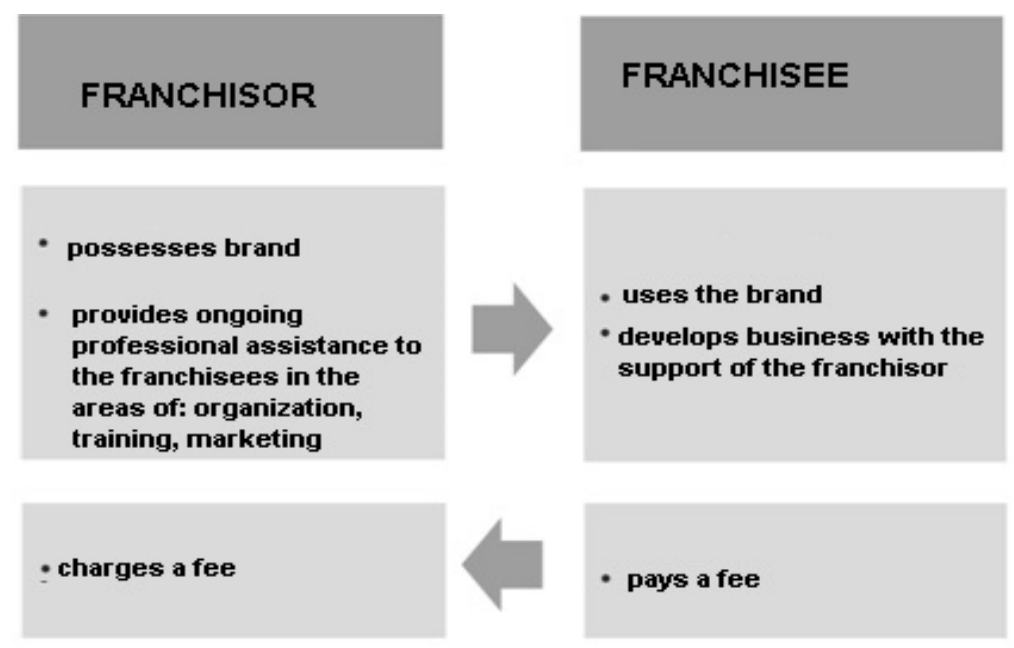

Fig. 1. Basic concepts of franchising

The figure clearly shows that franchising implies that a franchisee transfers an existing successful business model to another company franchisee. The franchisee pays financial compensation and complies with agreed standards of conduct.

The balance of small business [5] specifically emphasizes that each franchise system has one unique franchise offer, but opening and managing a system of individual owners will rarely and may never be as predicted, contracted and signed. Therefore, it is important that strategic and operational business decisions rest on the specifics and opportunities prevailing in the region or local community where the new franchise opens. Only in this way, it is possible to design one's own franchise offer and have a proper business case that will enable you to realistically attract and expand your own franchise system as planned. It is necessary to ensure that the franchisee's own offerings, legal contracts, fees and support structures are in line with the longterm development strategy and, in particular, the marketing strategy if the intended results are to be achieved.

\section{Franchises in Serbia - The Basic Elements of Success and Economic Indicators of Business}

The main goal of every company, even the franchise, as an entrepreneurial model, is profitable business. Franchising is an investment that is subject to economic evaluation and cost-effectiveness. Franchise investments are complex business ventures that require the involvement of financial resources and the realization of which takes a long time. In order to evaluate the project as a successful business venture and to ensure a turning point of profitability within a favourable period, cost-benefit analysis is strongly supported in evaluating the costeffectiveness of the project solution.

There are several methods to evaluate the effectiveness of investment projects. They have in common that they are all based on an evaluation and comparison of the volume of investments made and the future economic benefits of those investments. When evaluating franchise investments, we start with the simplest valuation method - the payback period. 
1. The Payback Period is the number of years required for a project to cover its initial investment, i.e., the period in which the amount of cash inflows will be equal to the initial outflow. The calculation of the payback period is based on the prediction of net cash flows for the first few years and a comparison of their accumulated value with investment outflows.

This investment criterion does not require discounting of cash flows, which reflects its advantage. It is the simplest indicator that points to the liquidity of the observed investment, as it shows the length of the "relatedness" of the financial resources in the project. It does not allow us to determine the real profitability of the invested project. The payback period is calculated using the formula

$$
\mathrm{PP}=\frac{\text { Value of Initial Investment (II) }}{\text { Annual Cash Flow }(\mathrm{CF})}
$$

It is important to emphasize that for the purposes of the analysis that follows, a projection of the value of investments and cash inflows was made, based on the business data of the observed companies for 2018 from the financial statements available on the website of the Agency for Business Registers. The projected value of the investment was calculated as a ratio of the total invested assets and the number of business objects, while the projection of cash inflows was calculated as a ratio of cash flows from business activities and the number of business objects.

Table 1. Return period for several leading franchises in Serbia

\begin{tabular}{|l|r|r|r|r|}
\hline & Mc Donalds & \multicolumn{1}{l|}{ Uniqua } & \multicolumn{1}{l|}{ Trafika } & \multicolumn{1}{l|}{ Dve šmizle } \\
\hline 1. The value of the investment (in $€)$ & 1.000 .000 & 7.500 & 1.500 & 6.000 \\
\hline 2.Projected cash inflows (in $€$ ) & 200.000 & 3.000 & 3.000 & 2.000 \\
\hline Period of return (1/2) & 5 & 2 & 0,5 & 3 \\
\hline
\end{tabular}

Source: Budgets made on the basis of data downloaded from the Business Registers Agency, which can be accessed at: https://tinyurl.com/sygdgbp

The criterion for accepting an investment in a given franchise is a return period that is lower than a predefined standard.

2. Investment efficiency ratio, known as the Accounting Rate of Return. The second method for evaluating investments is the relative ratio of the projected profit expected to the average amount of investment. The investment efficiency ratio is calculated using the formula:

$$
\mathrm{ARR}=\frac{\text { Average Annual Profit }}{\text { Average amount of investment }}
$$

The criterion for a positive evaluation of an investment project is an accounting rate of return that is higher than the expected return. To calculate ARR, we assume that profitability flows are equivalent to cash flows.

Table 2. Summary of investment efficiency ratios for several leading franchises in Serbia

\begin{tabular}{|l|r|r|r|r|}
\hline & Mc Donalds & \multicolumn{1}{|c|}{ Uniqua } & \multicolumn{1}{c|}{ Trafika } & \multicolumn{1}{c|}{ Dve šmizle } \\
\hline 1. The value of the investment $($ in $€)$ & 1.000 .000 & 7.500 & 1.500 & 6.000 \\
\hline 2.Projected cash profit (in $€$ ) & 200.000 & 3.000 & 3.000 & 2.000 \\
\hline Period of return $(2 / 1)$ & $20 \%$ & 2 & 0,5 & 3 \\
\hline
\end{tabular}

Source: Budgets made on the basis of data downloaded from the Business Registers Agency, which can be accessed at: https://tinyurl.com/wwztqar, [Accessed: 20 May 2019].

The main disadvantage of the previous two methods for evaluating investment is to neglect the time value of money. 
3. The Net Present Value (NPV) method is the difference between the present value of net cash flow from the exploitation of a project and the capital expenditure made in that project.

Most often, the standard rate of return is the discount rate at which future cash flows are reduced to their present value.

$$
\mathrm{NPV}=\sum_{\mathrm{t}=1}^{\mathrm{n}} \frac{\mathrm{CF}_{\mathrm{t}}}{(1+\mathrm{k})^{\mathrm{t}}}-\mathrm{CF}_{0}
$$

Dynamic methods of ranking investment projects respect the concept of time value of money. This concept is explained by the claim that a dinar today is worth more than the dinar that will be received tomorrow or anytime later. This is explained by the understanding that the dinar today can be immediately invested in a business in order to obtain a return from its use.

Table 3. Net present value for several leading franchises in Serbia

\begin{tabular}{|l|r|r|r|r|}
\hline & Mc Donalds & Uniqua & Trafika & Dve šmizle \\
\hline NPV & 544.200 & 15.663 & 21.663 & 9.442 \\
\hline
\end{tabular}

Source: Calculations were made on the basis of data downloaded from the Business Registers Agency, which can be accessed at: https://bit.ly/35Xqd8p, [Accessed: 20 May 2019].

An estimated 5\% discount rate over a ten-year period was used to calculate the NPV.

The decision rule is: if the NPV is greater than zero, the project should be accepted. This method is considered particularly suitable for the evaluation of successive investment projects in several stages.

4. The profitability index, in contrast to the previous method, relativizes profitability, expressing it in percentages:

$$
\text { Profitability index }=\frac{\text { The present value of net cash flow }}{\text { The present value of capital expenditure }}
$$

A project is considered worthwhile if the PI is greater than one because the present inflow value is greater than the present outflow value.

Table 4. Profitability index for several leading franchises in Serbia

\begin{tabular}{|l|r|r|r|r|}
\hline & Mc Donalds & Uniqua & Trafika & Dve šmizle \\
\hline Index & 1,54 & 3,09 & 15,44 & 2,57 \\
\hline
\end{tabular}

Source: Calculations were made on the basis of data downloaded from the Business Registers Agency, which can be accessed at: https://bit.ly/2TutKIH, [Accessed: 20 May 2019].

5. The lower point of profitability is an analysis of the financial performance of the business under consideration, derived from a profitability account that should show whether a project is financially viable. Within the profitability account, particular importance is attached to determining the level of the break-even point, which indicates the necessary level of revenue necessary to cover the total operating costs.

$$
\mathrm{CVP}=\frac{\text { Total fixed costs }}{\text { Contribution result rate }}
$$

All applied economic methods of calculating investment projects indicate that the observed franchising investments should be accepted as they do not require a long period of return on 
invested capital and implemented budgeting, and from the experience of already opened franchises it is shown that the investments are profitable in the planned period of ten years.

Different forms of risk can affect the expected outcome of an investment project. The risk itself implies the likelihood of an event that we do not want, which would mean that for the investment being made there will be a loss in the future due to insufficient, poorly available or even incorrect information when deciding on the investment itself. In order to manage the risk, it is necessary to analyze all potential threats that may affect the profitability of the investment in the future. One of the factors that determine the implementation of a franchisee start-up investment project is the living standard of the residents of a country, area or city where the potential investment would be initiated. In a multitude of living standards, the average monthly earnings of residents are highlighted.

\section{Franchises - A Profitable Business and the Standard of Living of the Population in Serbia}

The following analysis should examine whether the standard of living of the population in Serbia enables profitable business operations in all parts of the country. For the purposes of data analysis (testing of hypotheses and regression model creation), the following variables were observed: average earnings, the number of residents, and number of franchised facilities in a place or a specific area. From a measurement point of view the variable of average earnings are quantitatively continuous, while the variables the number of residents and number of franchise objects are quantitative discrete random variables. The SPSS software package was used for statistical data processing.

\section{The cost-effective franchise business in the area of services and the impact of the living standards of the residents}

Mc Donalds, Uniqua, Big blue and Trafika were observed for analysis. The total number of facilities in the territory of the Republic of Serbia is 44 . The average earnings and the number of residents in which the business facilities are located are observed, as can be seen in Table 5 .

Table 5. Number of franchise facilities, average earnings and the number of residents by city

\begin{tabular}{|l|r|r|r|}
\hline & Number of facilities & Average earnings & Number of residents \\
\hline Belgrade & 22 & 93024 & 1687132 \\
\hline Novi Sad & 7 & 91686 & 351126 \\
\hline Niš & 2 & 70103 & 256825 \\
\hline Subotica & 3 & 68949 & 137753 \\
\hline Kragujevac & 1 & 71846 & 177977 \\
\hline Velika Plana & 1 & 62050 & 38423 \\
\hline Pančevo & 1 & 75303 & 120361 \\
\hline Stara Pazova & 1 & 66102 & 65033 \\
\hline Užice & 1 & 72756 & 74371 \\
\hline Svilajnac & 1 & 59662 & 21690 \\
\hline Bogatić & 1 & 58407 & 26941 \\
\hline Sombor & 1 & 66903 & 80400 \\
\hline Sremska Mitovica & 1 & 68909 & 76499 \\
\hline Apatin & 1 & 64450 & 21107 \\
\hline
\end{tabular}

Source: The database for analysis has been formed on the databases of the Statistical Office of the Republic, which can be accessed at: http://data.stat.gov.rs/?caller=SDDB, [Accessed: 20 May 2019].

If we look at the earnings in places where there are franchise facilities, we can see that the average salary is RSD 70,725.00 with a standard deviation of RSD10,357.17. With a probability of $95 \%$, we claim that earnings range from $(64,744.95-76,705.05)$. We can also see that in $50 \%$ of cities, the salary is less than RSD 68,929.00. 


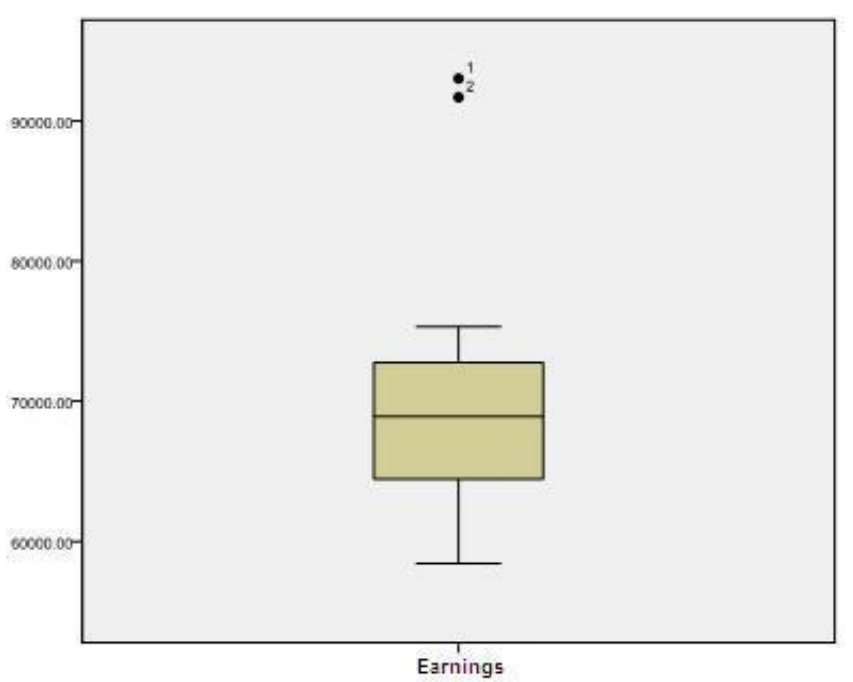

Chart 1. Average earnings in cities with franchise facilities Source: [6]

In Chart 1. we can see that there are influential points - i.e., observations that may affect the model below, in different ways, such as estimated coefficients or test results. Outlier- the value of a dependent variable that is quite different from the value predicted by the model, while for observations that have unusual predictor values, we say that they are high leverage.

It is very important here for our model to answer whether these points affect the model.

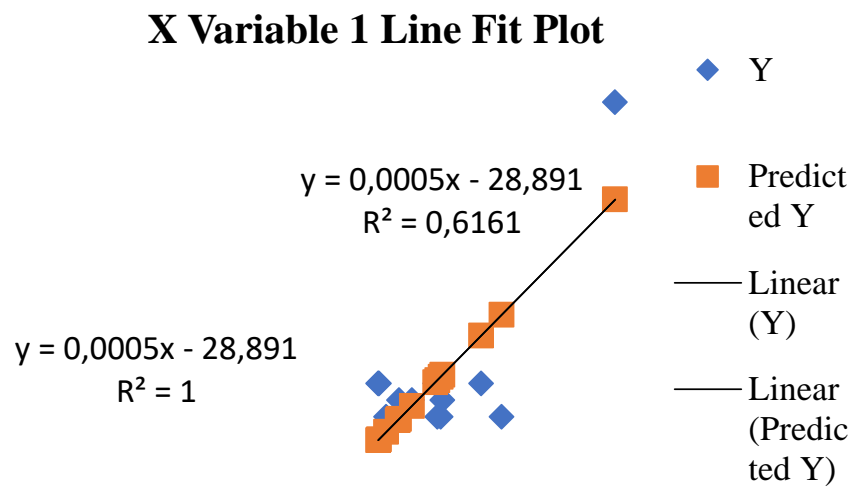

\section{Variable 1}

Chart 1.

As our point is an outlier, and as the values of the slope coefficients with and without the outlier are very similar $(0.0004$ and 0.0002 and also $\mathrm{r} 2$ in the second model is insignificantly higher -0.62 compared to 0.60 because we excluded point that deviates from other values), because of all these similarities we can conclude that the point is not influential even though it is an outlier.

If we observe a multiple regression equation showing the dependence of open restaurants on average earnings and the number of residents in a place or area (by which we can estimate the number of restaurants for a given average earnings and population), we get:

The Number of Restaurants $=\mathrm{a}_{0}+\mathrm{a}_{1} \times$ Average Earnings $+\mathrm{a}_{2} \times$ The Number of Residents

The Number of Restaurants $=-2,47+0,00004 \times$ Average Earnings $+0,00001 \times$ The Number of Residents 
Sig. $<0.05$, so the model is statistically significant, and as for the regression coefficients, the parameter a 2 is statistically significant because its $\mathrm{p}$-value is $<0.05$. We can observe that the coefficient of determination ( $\mathrm{r} 2$ ) is 0.97 , which means that we have $97 \%$ of the explained variability, which means that the number of objects varies $97 \%$ when the salaries and the population vary, and only $3 \%$ are some other unexplained factors.

Table 6. Linear regression coefficient values

\begin{tabular}{|l|r|r|r|r|}
\hline Model & \multicolumn{1}{|c|}{ Model Summary } \\
\hline 1 & $.986^{\mathrm{a}}$ & .973 & .968 & 1.010 \\
\hline
\end{tabular}

a. Predictors: (Constant), The number of residents, Earnings

Table 7. Coefficients

Coefficients $^{\mathrm{a}}$

\begin{tabular}{|c|c|c|c|c|c|c|}
\hline & & \multicolumn{2}{|c|}{$\begin{array}{l}\text { Unstandardized } \\
\text { Coefficients }\end{array}$} & \multirow{2}{*}{\begin{tabular}{|c|}
$\begin{array}{c}\text { Standardized } \\
\text { Coefficients }\end{array}$ \\
Beta \\
\end{tabular}} & \multirow[b]{2}{*}{ T } & \multirow[b]{2}{*}{ Sig. } \\
\hline \multicolumn{2}{|c|}{ Model } & B & Std. Error & & & \\
\hline \multirow[t]{3}{*}{1} & (Constant) & -2.469 & 2.750 & & -.898 & .389 \\
\hline & Earnings & $4.071 \mathrm{E}-5$ & .000 & .074 & .993 & .342 \\
\hline & $\begin{array}{l}\text { The number of } \\
\text { residents }\end{array}$ & 1. $220 \mathrm{E}-5$ & .000 & .929 & 12.411 & .000 \\
\hline
\end{tabular}

a. Dependent Variable: Number of facilities

If the policy of the franchisee company is to open business premises in cities with a minimum monthly earning of greater than 70,000, we can test at the $1 \%$ significance level the hypothesis that the company should open a facility in one of the 5 cities in the Raška region where the average salary is RSD 61,700, with a standard deviation of RSD 2,590.

We have that:

$$
H_{0}: \mu \geq 70000 \quad H_{1}: \mu<70000
$$

$$
\begin{array}{|l|l|} 
& \begin{array}{l}
n=5 \\
\mu_{0}=70000 \\
\bar{x}=61700 \\
s=2590 \\
\alpha=0,01
\end{array} \\
t=\operatorname{tinv}(0,02 ; 4)=3,75 \\
T_{S}=\frac{\bar{x}-\mu_{0}}{\frac{s}{\sqrt{n}}}=\frac{61700-70000}{\frac{2590}{\sqrt{5}}}=-7,18
\end{array}
$$

Since $\mathrm{Ts}<3.75$, the null hypothesis is rejected, so the company should not open a facility in the observed Raška region.

\section{The Profitable Business of Franchises in the Field of Trade and the Impact of yhe Living Standard of Residents}

In the table below, for the purposes of analysis, the companies "Trafika" and "Dve Šmizle" were observed. 
Table 8. The number of franchise facilities, average earnings and the number of residents by regions

\begin{tabular}{|c|c|c|c|c|}
\hline Region & Number of facilities & Average earnings & Number of residents & $\%$ of residents \\
\hline Belgrade region & 20 & 93024 & 1687132 & $24,03 \%$ \\
\hline West Bačka region & 1 & 64177 & 175347 & $2,50 \%$ \\
\hline South Bačka region & 3 & 75255 & 617949 & $8,80 \%$ \\
\hline Middle Bačka region & 1 & 69859 & 177308 & $2,53 \%$ \\
\hline Srem region & 2 & 66057 & 300988 & $4,29 \%$ \\
\hline Kolubara region & 1 & 69420 & 165273 & $2,35 \%$ \\
\hline Mačva region & 1 & 62658 & 283007 & $4,03 \%$ \\
\hline Morava region & 2 & 64359 & 202026 & $2,88 \%$ \\
\hline Pomoravlje region & 3 & 61584 & 202025 & $2,88 \%$ \\
\hline Raška region & 3 & 61700 & 305954 & $4,36 \%$ \\
\hline Šumadija region & 3 & 69159 & 284957 & $4,06 \%$ \\
\hline Bor region & 1 & 77980 & 114816 & $1,64 \%$ \\
\hline \multirow[t]{2}{*}{ Danube region } & 2 & 70105 & 189091 & $2,69 \%$ \\
\hline & 43 & & & $67,03 \%$ \\
\hline
\end{tabular}

Source: [6]

The average earnings in the areas where franchisees operate is RSD 69,641.31, with a standard deviation of RSD 8,639.55. The 95\% confidence interval for average earnings moves into the interval $(64,420.48-74,862.13)$. The coefficient of variation for average earnings is $12.41 \%$, so the data in the series are homogeneous.

The correlation coefficient for population and average earnings is $r=0.78$, so the relationship is strong, while the correlation coefficient for variables the number of facilities and population is $r=0.97$, so the relationship is very strong.

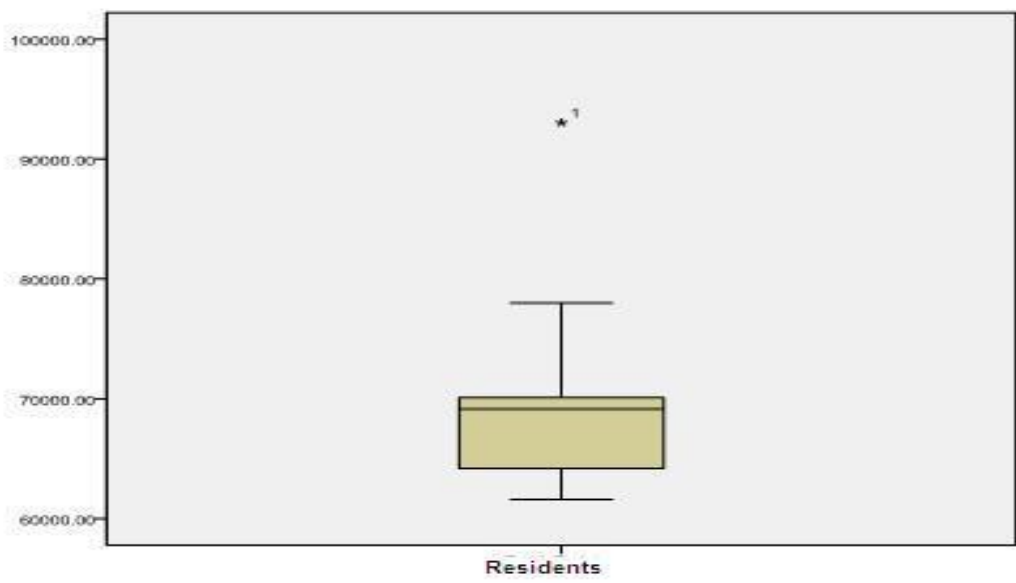

Chart 3. The number of residents in areas with franchise facilities Source: [6]

Should a company intend, or was it a business decision, to open facilities in areas with an average population of at least 250,000 , we can test the hypothesis of whether to open facilities in any of the 5 observed areas with an average population of 224,134 with standard deviation of 57,574 , at a significance level of $0.05 \%$.

$$
H_{0}: \mu \geq 250000 \quad H_{1}: \mu<250000
$$

We have that: 


$$
\begin{array}{|l|l|} 
& \begin{array}{l}
n=5 \\
\mu_{0}=250000 \\
\bar{x}=224143 \\
s=57574 \\
\alpha=0,05
\end{array} \\
t=\operatorname{tinv}(0,1 ; 4)=2,13 \\
T_{S}=\frac{\bar{x}-\mu_{0}}{\frac{s}{\sqrt{n}}}=\frac{224143-250000}{\frac{57574}{\sqrt{5}}}=-1,01
\end{array}
$$

Since Ts $<2.13$, the null hypothesis is rejected, so the company should not open a facility in the observed areas with an average population of 224,143 .

\section{Conclusion}

The Republic of Serbia is a great untapped potential for franchise investments, as a modern business form of international financing, given the very low percentage of franchisees' participation in the total turnover of the country. In order for franchising to be the basic way of entrepreneurial investment, it is necessary to ensure an adequate market climate accompanied by appropriate legislation and the necessary enforcement institutions. Previous economic analyzes of the costeffectiveness of franchise investments have indicated the justification of the investments themselves, given that areas that would be a potential destination for investment must be taken into account, all related to average earnings and population in the area. The number of residents has proven to be a significant factor in business decision-making, as business facilities can reasonably be opened in areas with an average population of about $3.33 \%$ of the total population. In less populated areas it is justified to open franchises if they are located in high-frequency locations such as highways or tourist destinations visited by a large number of both domestic and foreign tourists or persons in transit. It is also significant that for management, in addition to all the indicators analyzed, it is very important to maintain standards that include recognizable appearance, standard quality offer, well-trained staff and everything else that the brand carries with it.

\section{REFERENCES}

1. Delaney, L. (2018) A Global Strategic Guide to International Franchising, available at https://www.thebalancesmb.com/international-franchising-a-global-strategic-initiative-1953329 [Accessed: 24 June 2019].

2. Stanton, M (2019) 5 factors franchisees must know before signing on the dotted line, available at https://www.franchise.org/franchise-information/franchise-development/5-factors-franchisees-mustknow-before-signing-on-the-dotted-line [Accessed: 24 June 2019].

3. Franchising World (June 2019), available at https://mydigitalpublication.com/publication/?i=592544\# \{\%22issue_id\%22:592544,\% 22page\%22:64\} [Accessed: 24 June 2019].

4. Brown, H. (1969), Franchising, Trap for Trusting, Boston: Appendix A.

5. The balance small business (2019) Franchise Your Business: An Overview, available at https://www.thebalancesmb.com/franchise-your-business-an-overview-1349613 [Accessed: 24 June 2019].

6. T he Statistical Office of the Republic, http://data.stat.gov.rs/?caller=SDDB, [accessed: 20 May 2019].

\section{Article history:}

- $\quad$ Received 15 November 2019

- Accepted 20 December 2019 